\title{
Calibration of micro-simulation model in assessment of passenger car exhaust emission during acceleration
}

ARTICLE INFO

Received: 27 August 2021

Revised: 21 September 2021

Accepted: 23 September 2021

Available online: 4 October 2022
In terms of simulation research, it is important to simulate real conditions as precisely as possible. This type of approach makes it possible to minimize the error in the obtained results. The dynamics of acceleration is one of the most important factors having a direct impact on fuel consumption and exhaust emissions from vehicles. The work was carried out with the use of PTV Vissim microscopic vehicle motion simulation software. The considerations were carried out on theoretical acceleration profiles with different dynamics values and the actual character of acceleration, recorded during road tests. The simulations were carried out for a car powered by spark-ignition and compression-ignition engines. The research showed that the calibration of the acceleration character of the vehicle in simulation tests may result in significant differences in obtained results of exhaust emissions.

Key words: exhaust emission, simulation, vehicle acceleration, model calibration, acceleration dynamics

This is an open access article under the CC BY license (http://creativecommons.org/licenses/BY/4.0/)

\section{Introduction}

Operating conditions have a direct impact on fuel consumption and the emission of harmful exhaust compounds. Different operating conditions of propulsion systems in vehicles during type-approval measurements and during actual operation lead to over $90 \%$ difference in the average fuel consumption $[8,11]$. Also, the results of measurements taken under real-life conditions differ significantly depending on the driving style $[1,4,7]$. In other works, apart from the driving style of the driver, the differences in fuel consumption or energy consumption refer to the intensity of vehicle traffic and the road congestion [3, 5]. The road congestion and in particular traffic jams, are the domain of cities with a large number of inhabitants $[2,13]$. In such a situation, vehicles emit pollutants in the immediate vicinity of large numbers of people. Some publications consider the influence of the acceleration dynamics on the emission of harmful exhaust compounds, but these works are conducted in real driving conditions [12]. The traffic simulation software could be used also to solve some infrastructure problems. An example is a research, which describes the influence of rai-road level crossing on the road traffic flow [a9]. Such approach to transport engineering could result in obtaining some low cost quantitative data, which could be helpful in future infrastructure development or could give a positive feedback, which will result in further, more expensive research work.

In simulation works the traffic model should be calibrated properly, e.g. in terms of the acceleration characteristics of a single vehicle (could be also adopted to different vehicle categories), number of vehicles driving on selected roads, etc. Lack of proper calibration in terms of simulation model may contribute to significant discrepancies of obtained results in relation to the real values [10]. This study focuses on the assessment of the impact of the acceleration dynamics of a passenger vehicle up to a speed of approx. 50 $\mathrm{km} / \mathrm{h}$ on the results of exhaust emissions. For this purpose, the vehicle acceleration curve was adapted to the model of the actual vehicle acceleration recorded during the road test.

\section{Research methodology}

The simulation tests were performed with the use of Vissim software, version 5.40, which was developed by the German company PTV. This software is commonly used by companies working in the field of traffic engineering and road managers. The tool is used to simulate vehicle traffic on a microscopic scale, which means that the best results can be obtained by analyzing small areas, including, for example, a certain road section, intersection or a small traffic area. Another type of software (eg PTV Visum) is used to analyze larger areas, eg a whole city. The advantage of the software used is the implemented vehicle traffic models, including cars, trucks, buses and trams. The analyzes can also take into account the pedestrians or cyclists. With use of an additional modules, it is possible to perform different analyzes related to, for example, exhaust emissions from vehicles moving in the modeled part of the road infrastructure.

As a part of the performed simulations, the emissivity of passenger cars representing the Euro 3 emission standard for various acceleration scenarios was assessed. Modeling included tests of accelerating a vehicle to approx. $50 \mathrm{~km} / \mathrm{h}$. For this purpose, a road section was modeled, mapping a fragment of Kornicka Street in Poznan (Fig. 1). In order to simplify the model, the traffic of vehicles was mapped only on Kornicka Street in the analyzed direction. Only vehicles taking off from a standstill were taken into account (initial speed $V_{0}=0 \mathrm{~km} / \mathrm{h}$ ). As the vehicles entering the model have an initial speed greater than $0 \mathrm{~km} / \mathrm{h}$, they were forced to stop with use of traffic lights. Some of the vehicles entering the model stopped at the aforementioned traffic lights located along the analyzed street, which made it possible to obtain data for further analysis.

In the first order, the acceleration of passenger cars was simulated, using the acceleration values implemented in the simulation software, using the levels $1.0 \mathrm{~m} / \mathrm{s}^{2}, 1.2 \mathrm{~m} / \mathrm{s}^{2}$ and 
$2.5 \mathrm{~m} / \mathrm{s}^{2}$. The obtained acceleration curves in function of simulation time were characterized by nearly rectangular shapes (Fig. 2). Because the obtained characteristics to a small extent reflect the nature of the actual acceleration of the vehicle, driven by a human, during which it is almost impossible to obtain such simple shapes of acceleration character. This is all the more justified as in most acceleration situations to around $50 \mathrm{~km} / \mathrm{h}$, when also the gear shifting must be taken into account. For comparison, the character of selected acceleration of a light passenger-goods vehicle recorded during a road test is presented (Fig. 3). The next step was to adapt the acceleration curve of the vehicle so that its course during the simulation was similar to the characteristics recorded during the actual tests.

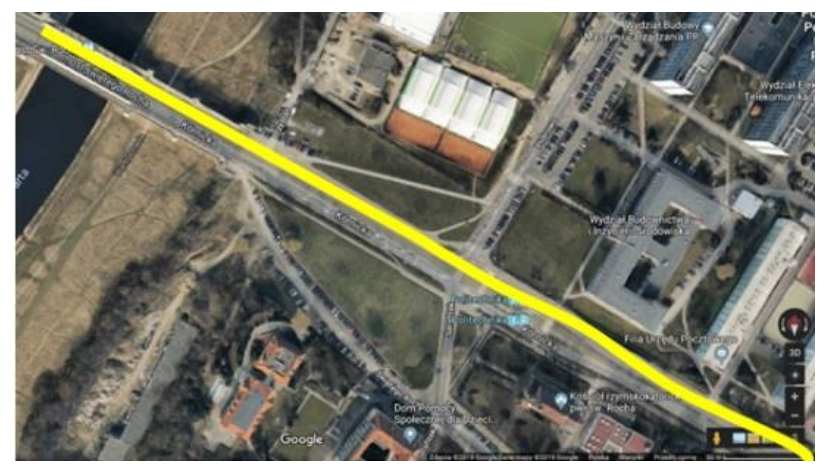

Fig. 1. Section of Kornicka Street in Poznan, used in this work for vehicles acceleration modeling [6]

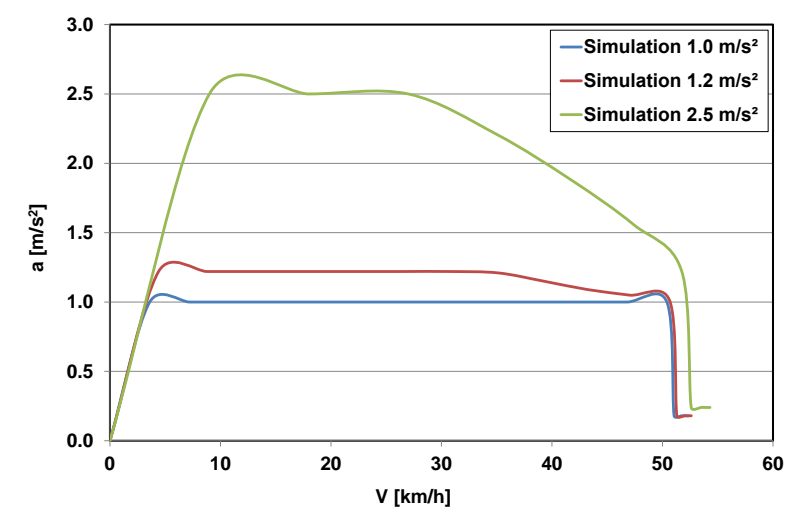

Fig. 2. Vehicle acceleration characteristics, obtained in the PTV Vissim software, obtained on the basis of the implemented data $\left(1.0 \mathrm{~m} / \mathrm{s}^{2}, 2.0\right.$ $\left.\mathrm{m} / \mathrm{s}^{2}, 2.5 \mathrm{~m} / \mathrm{s}^{2}\right)$

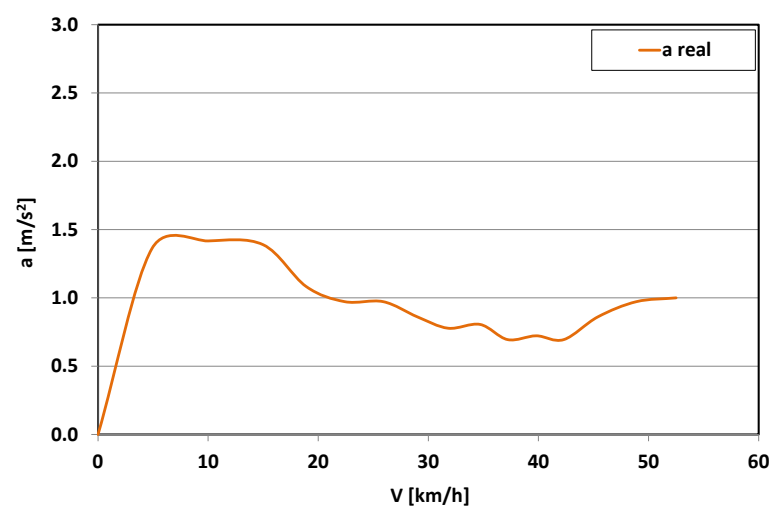

Fig. 3. The acceleration characteristics of the vehicle recorded during the actual acceleration test
The adaptation of the simulation in order to make the acceleration curve similar to the curve recorded during the real drive was carried out in many stages. During early attempts, the vehicle acceleration values were not sufficiently high immediately after starting (the acceleration curve was more inclined than during the actual measurement). In the next stage, the acceleration of some vehicles was disturbed by the slower accelerating vehicles in front. Some examples of the mentioned situations are shown in Fig. 4. The situation related to the influence of the preceding vehicles on the acceleration of the analyzed vehicle is related to the use of traffic lights in order to force the vehicle to accelerate from standstill. In the described situation, it happens that several vehicles accumulates at the red light because the vehicles are directed to the model at the intensity specified by the author. The above-mentioned model imperfections do not occur in the analyzed acceleration cases. The obtained acceleration waveforms are also not the same, which reflects the stochastic nature of the actual vehicle acceleration process and the lack of full repeatability during acceleration by the real driver in real traffic conditions.

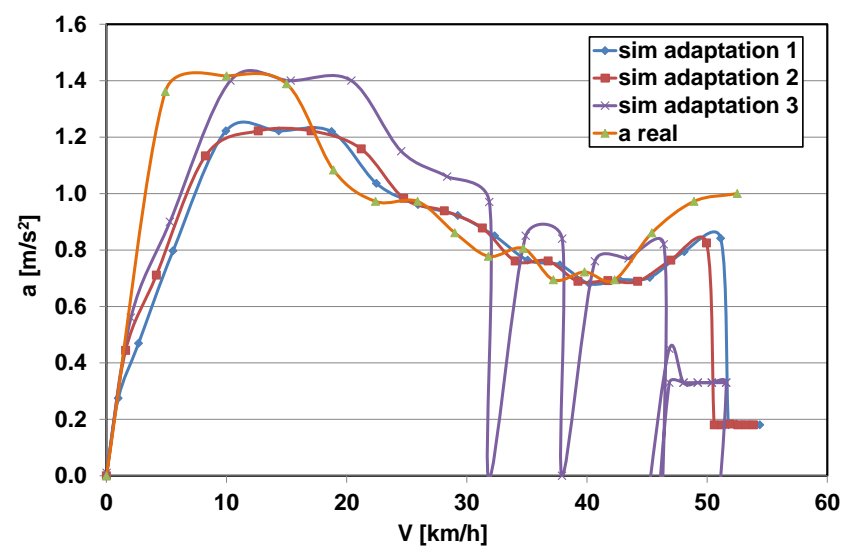

Fig. 4. The process of adaptation characteristics of acceleration of the vehicle in PTV Vissim

\section{Research results}

During the simulation, two types of data were collected: the speed and acceleration profiles of the vehicle during acceleration and the changes in the intensity of emissions of individual exhaust components depending on the time of simulated acceleration.

Examples of the characteristics of speed and acceleration in time for the given vehicle acceleration conditions are shown in Fig. 5-8. The acceleration generated by the Vissim software is characterized by a waveform with a shape similar to a rectangle, which especially applies to the acceleration values of $1.0 \mathrm{~m} / \mathrm{s}^{2}$ and $1.2 \mathrm{~m} / \mathrm{s}^{2}$ (Fig. 5-6). The nature of acceleration also translates into a change in speed over time, which for the two cases discussed above has the shape of a straight line. The acceleration with a maximum value of $2.5 \mathrm{~m} / \mathrm{s}^{2}$ (Fig. 7) is of a nature that to a greater extent reflects the acceleration modeled on the real test (Fig. 8), obtaining only higher values. During the analyzed case of real acceleration, it is characteristic that the maximum value of the vehicle acceleration is approx. $1.2 \mathrm{~m} / \mathrm{s}^{2}$. Moreover, the course of the acceleration value as a function 
of the vehicle speed is much more complicated than in the previous cases. This is due to circumstances such as gear changes or the characteristics of the engine used.

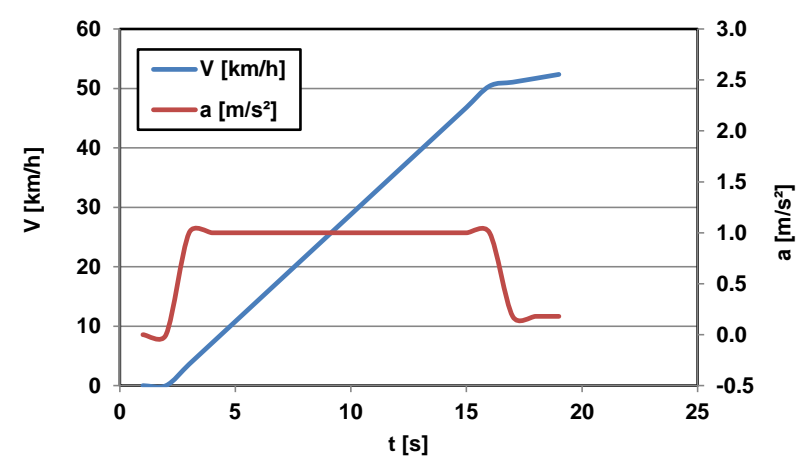

Fig. 5. Characteristics of speed and acceleration of the vehicle as a function of simulation time; $\mathrm{a}=1.0 \mathrm{~m} / \mathrm{s}^{2}$

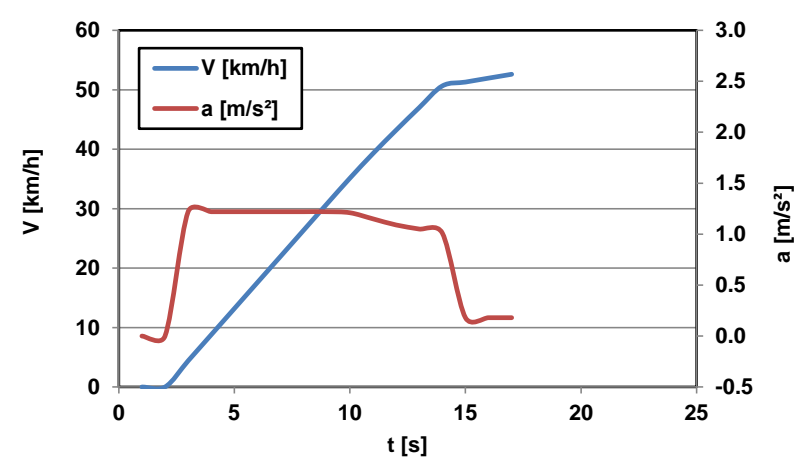

Fig. 6. Characteristics of speed and acceleration of the vehicle as a function of simulation time; $a=1.2 \mathrm{~m} / \mathrm{s}^{2}$

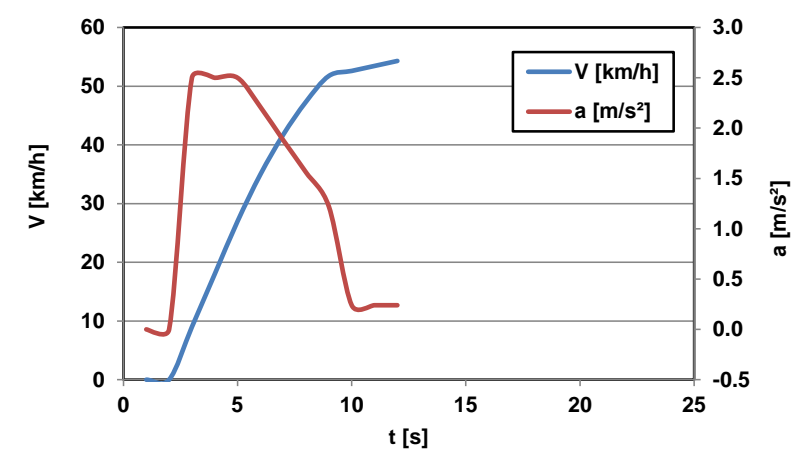

Fig. 7. Characteristics of speed and acceleration of the vehicle as a function of simulation time; $a=2.5 \mathrm{~m} / \mathrm{s}^{2}$

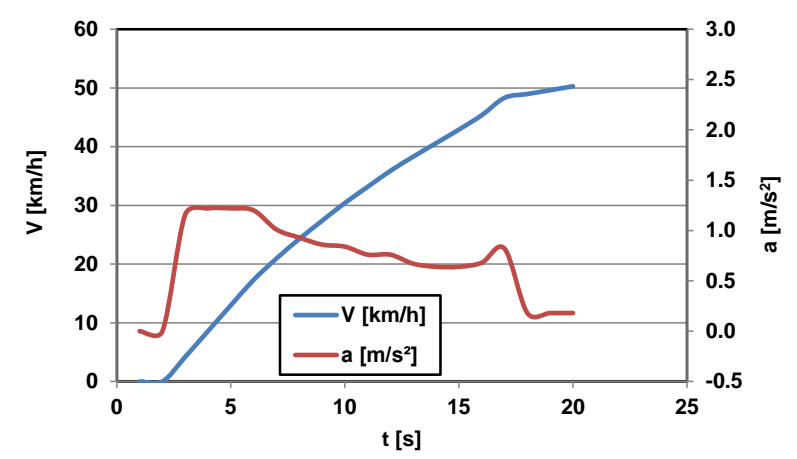

Fig. 8. Characteristics of speed and acceleration of the vehicle as a function of simulation time; mapped on the basis of a real acceleration test
The exhaust emission intensity as a function of time during the acceleration of the vehicle is shown in Fig. 9-12. The presented data was obtained during a simulated acceleration of a passenger car, compliant with the Euro 3 emission standard, while the variable parameter was the acceleration, the course of which for considered cases was presented in Fig. 5-8. The trends that can be observed in the presented graphs of the emission intensity of individual exhaust gas components are predictable and are consistent with the general relationships concerning the formation of toxic compounds in combustion engines. The greater the acceleration value, the greater the exhaust emission rate, expressed in grams per second. The greatest differences between analyzed acceleration scenarios can be observed for the $\mathrm{NO}_{\mathrm{x}}$ and $\mathrm{CO}_{2}$ emission rates. The greater the acceleration value, the greater the load on the drive unit, which results in higher pressure and temperature values in the combustion chamber. Increasing these two parameters promotes the formation of $\mathrm{NO}_{\mathrm{x}}$. The highest intensity of $\mathrm{NO}_{\mathrm{x}}$ emission occurs during acceleration with the highest acceleration value $\left(2.5 \mathrm{~m} / \mathrm{s}^{2}\right)$ and it reaches the maximum value at the level of approx. $40 \mathrm{mg} / \mathrm{s}$, which is almost $100 \%$ more than during acceleration with the acceleration value of 1.0 $\mathrm{m} / \mathrm{s}^{2}$. The lowest maximum value of the instantaneous $\mathrm{NO}_{\mathrm{x}}$ emission intensity was recorded for the acceleration modeled on the real test. It is certainly related to the course of the acceleration curve as a function of time. The maximum value of acceleration for the case shown in Fig. 12 is kept in the vehicle speed range at the level of approx. $5-18 \mathrm{~km} / \mathrm{h}$, while at higher values of the vehicle speed, the acceleration value decreases. The rate of $\mathrm{CO}_{2}$ emissions relates directly to the instantaneous fuel consumption. Therefore, for this benchmark, similar trends can be observed as for $\mathrm{NO}_{\mathrm{x}}$. For example, the maximum rate of $\mathrm{CO}_{2}$ emission for an acceleration of $1.0 \mathrm{~m} / \mathrm{s}^{2}$ is approx. $5.3 \mathrm{~g} / \mathrm{s}$, while for $2.5 \mathrm{~m} / \mathrm{s}^{2}$, this parameter reaches the value of approx. $7 \mathrm{~g} / \mathrm{s}$, which increases the value of this parameter by over $30 \%$. Similar trends can be observed in the case of $\mathrm{CO}$ and $\mathrm{HC}$ emissions, but the differences in this case are not so significant. This is probably related to the improvement of the combustion quality at higher engine load, which results in a lower concentration of incomplete combustion products, however, it is compensated by the higher exhaust gas flow caused by the higher engine load and/or higher rotational speed.

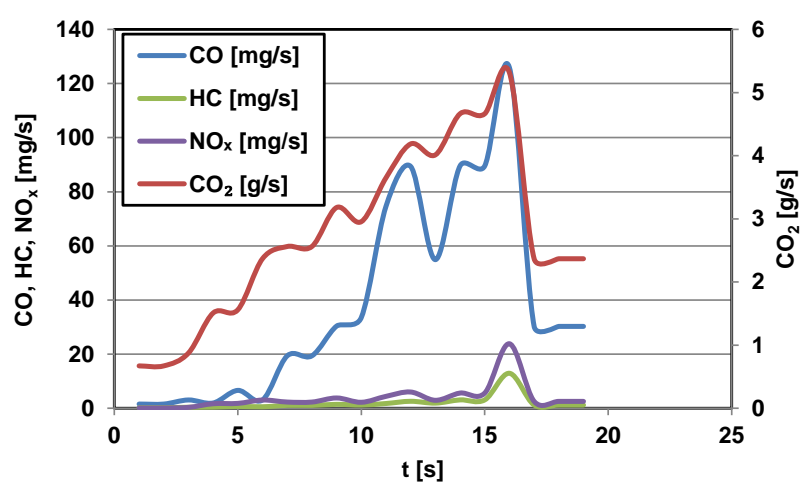

Fig. 9. Emission rates of individual exhaust gas components as a function of simulation time for: $\mathrm{a}=1.0 \mathrm{~m} / \mathrm{s}^{2}$ 


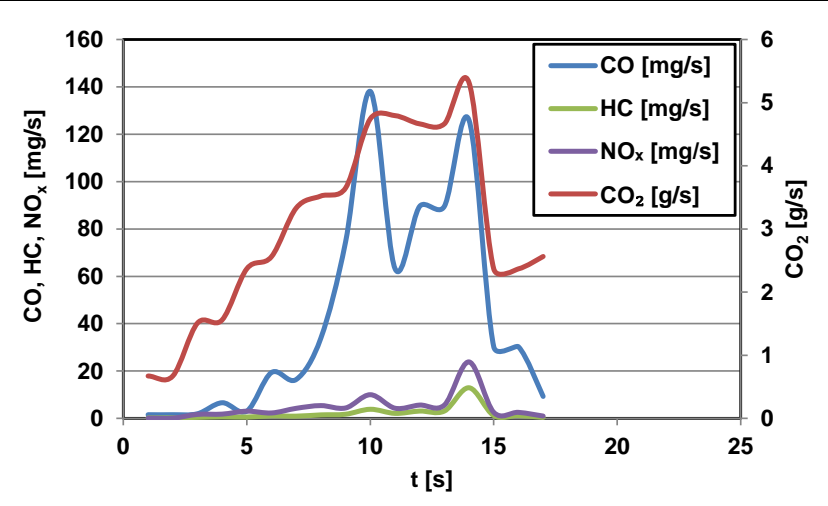

Fig. 10. Emission rates of individual exhaust gas components as a function of simulation time for: $\mathrm{a}=1.2 \mathrm{~m} / \mathrm{s}^{2}$

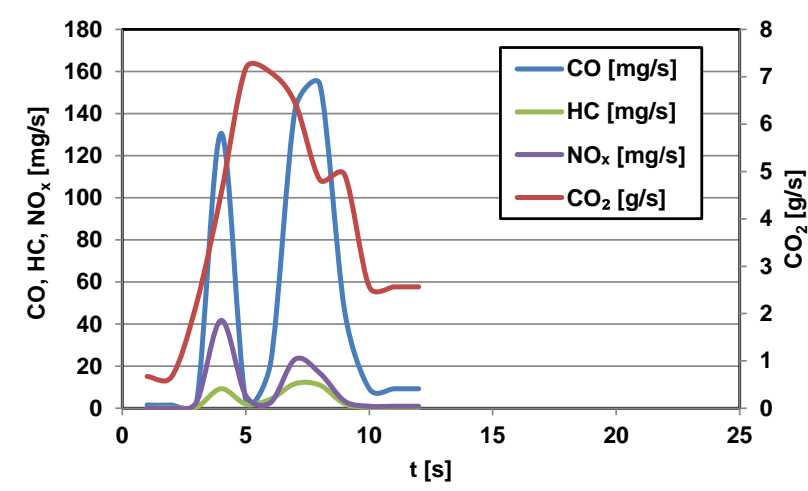

Fig. 11. Emission rates of individual exhaust gas components as a function of simulation time for: $\mathrm{a}=2.5 \mathrm{~m} / \mathrm{s}^{2}$

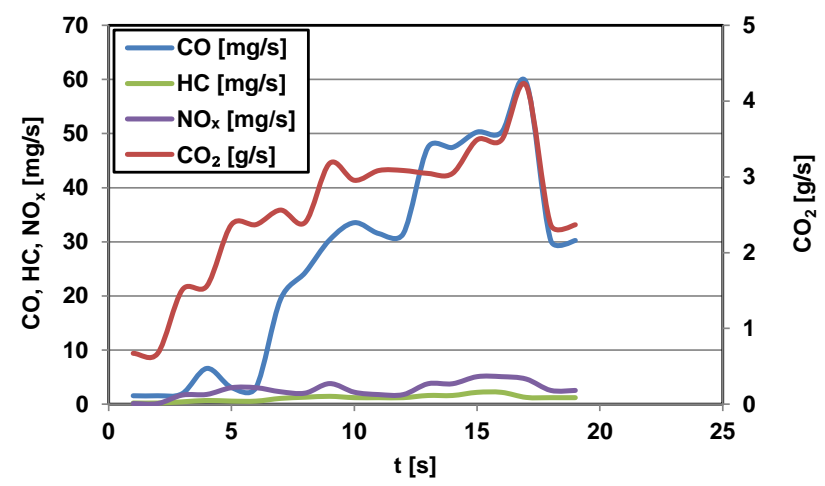

Fig. 12. Emission intensities of individual exhaust gas components as a function of simulation time for the acceleration mapped on the basis of the actual acceleration test

The influence of the value and course of the vehicle acceleration on the emission of the analyzed exhaust gas components is shown in Fig. 13-20. In this case, the cumulative mass of individual exhaust gas compounds was presented for the entire acceleration phase from a standing start to approx. $50 \mathrm{~km} / \mathrm{h}$. The figures have been grouped by two, consecutively for $\mathrm{CO}, \mathrm{HC}, \mathrm{NO}_{\mathrm{x}}$ and $\mathrm{CO}_{2}$, with the first data for vehicles powered by SI engines, followed by the data for cars with CI engines. The above-mentioned drawings were prepared based on the simulation results for cars with engines meeting the Euro 3 emission standard, which is still popular among vehicles traveling on the roads in Poland.

Higher acceleration means a higher temperature in the combustion chamber, which contributes to the improvement of combustion conditions, and therefore the concentration of incomplete combustion products (e.g. CO) is reduced. In the graphs, it is difficult to notice a significant reduction in the $\mathrm{CO}$ emission between an acceleration of $1.0 \mathrm{~m} / \mathrm{s}^{2}$ and $2.5 \mathrm{~m} / \mathrm{s}^{2}$. This is related to a greater exhaust gas flow during a more dynamic acceleration of the vehicle. For the analyzed case (Euro 3 emission standard), a vehicle powered by a compression ignition engine emitted more than 10 times less $\mathrm{CO}$ than a vehicle powered by a spark ignition engine.

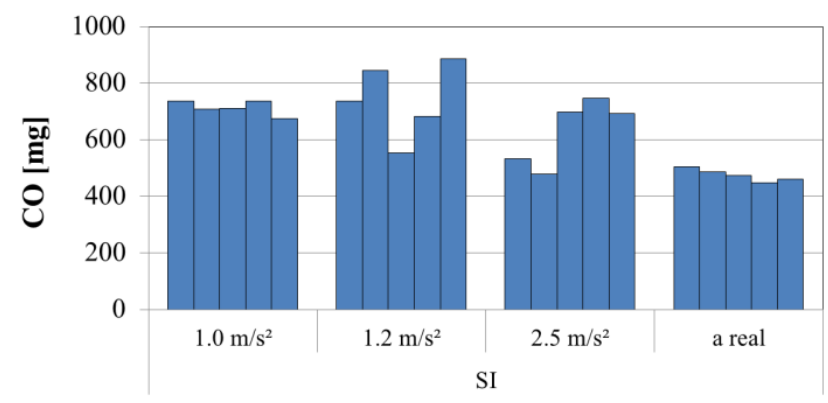

Fig. 13. CO emissions for different acceleration characteristics of a vehicle propelled with SI Euro 3 engine obtained during simulation using PTV Vissim software

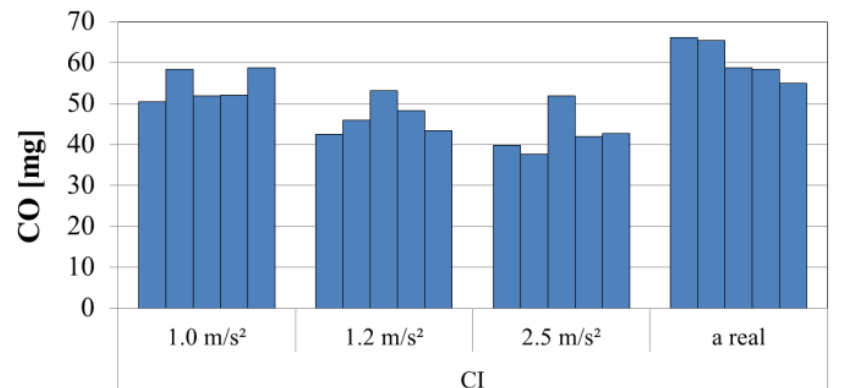

Fig. 14. CO emissions for different acceleration characteristics of a vehicle propelled with SI Euro 3 engine obtained during simulation using PTV Vissim software

As in the case of $\mathrm{CO}$, the concentration of $\mathrm{HC}$ in the exhaust gas should be lower under the conditions of more dynamic acceleration of the vehicle. HC emission during the analyzed cases of acceleration of vehicles with SI engines, ranges from approx. $20-70 \mathrm{mg}$, while values exceeding $40 \mathrm{mg}$ were obtained in individual cases and could be caused by a temporary change in the acceleration value of the vehicle. The lowest values of $\mathrm{HC}$ emissions were obtained for the acceleration selected on the basis of the actual test, which is certainly related to the different characteristics of the vehicle acceleration - in this case, the acceleration value of the vehicle decreases with the increase in its speed, which is a natural situation. The dependencies related to the influence of the vehicle acceleration dynamics on the $\mathrm{HC}$ emission from cars powered by $\mathrm{CI}$ engines are slightly different than those observed in the case of vehicles powered by SI engines. In this case, there is a slight reduction in $\mathrm{HC}$ emission as a function of the acceleration value of the vehicle, and the obtained values are several times lower than during the acceleration of the vehicle with the SI engine. 


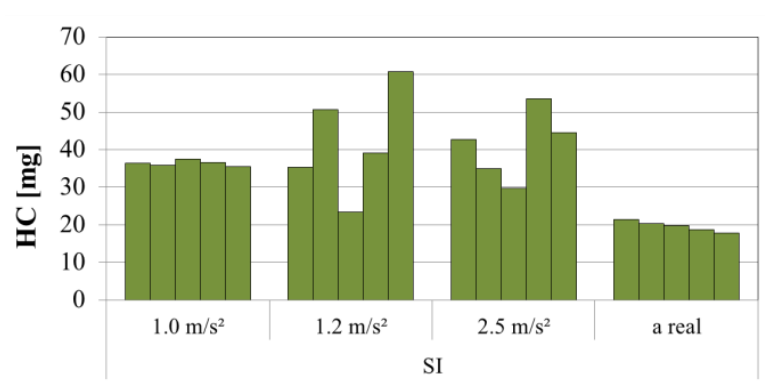

Fig. 15. HC emission for different acceleration characteristics of a vehicle propelled with SI Euro 3 engine obtained during simulation using PTV Vissim software

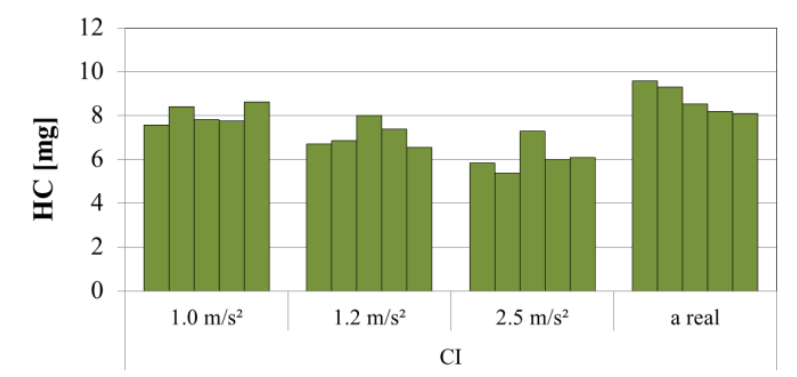

Fig. 16. HC emission for different acceleration characteristics of a vehicle propelled with CI Euro 3 engine obtained during simulation using PTV Vissim software

As the load on the drive unit increases, so does the $\mathrm{NO}_{\mathrm{x}}$ emission during the acceleration of the car with the SI engine. However, the observed differences amount to approx. 20-30\%. Much larger differences can be observed between the simulation of the highest acceleration dynamics and the acceleration recorded for the real test, when the $\mathrm{NO}_{\mathrm{x}}$ emission is lower by up to $60 \%$.

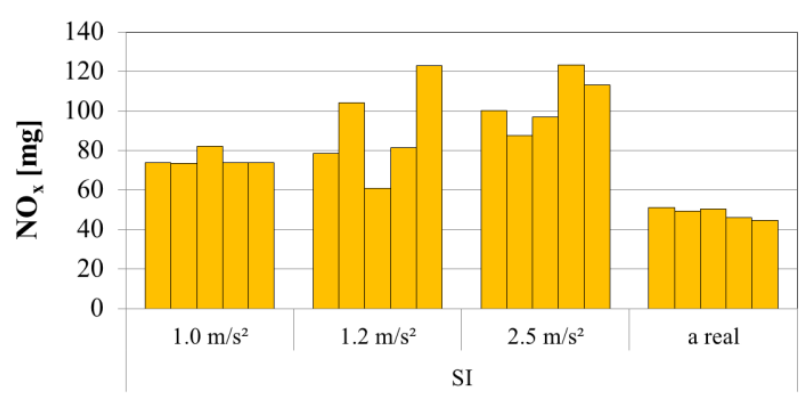

Fig. 17. $\mathrm{NO}_{\mathrm{x}}$ emission for different acceleration characteristics of a vehicle propelled with SI Euro 3 engine obtained during simulation using PTV Vissim software

During the simulation of vehicles acceleration propelled with diesel engines, a reduction in $\mathrm{NO}_{\mathrm{x}}$ emissions was observed as a function of the acceleration dynamics. The implementation of the actual vehicle acceleration curve contributed to a further reduction of the obtained results by approx. 10-15\% compared to the acceleration value of 2.5 $\mathrm{m} / \mathrm{s}^{2}$. Comparing the $\mathrm{NO}_{\mathrm{x}}$ emission registered for vehicles powered by $\mathrm{CI}$ engines with the emission obtained by vehicles with SI engines, it can be stated that the mass of this compound is 2-3 times higher during the acceleration of cars powered by CI engines. For example, in the case of acceleration modeled on the real test, cars powered by $\mathrm{CI}$ engines emitted approx. 42-50 mg of $\mathrm{NO}_{\mathrm{x}}$, while the mass of $\mathrm{NO}_{\mathrm{x}}$ from cars powered by diesel engines was approx. $110-145 \mathrm{mg}$. This is caused by using the three-way catalyst, which reduces the amount of $\mathrm{NO}_{\mathrm{x}}$ in exhaust gases.

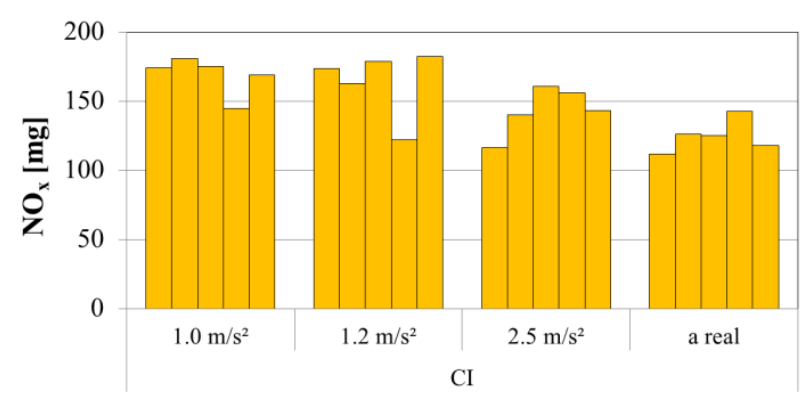

Fig. 18. $\mathrm{NO}_{\mathrm{x}}$ emission for different acceleration characteristics of a vehicle propelled with CI Euro 3 engine obtained during simulation using PTV Vissim software

The change in the acceleration dynamics did not significantly change the $\mathrm{CO}_{2}$ emissions from vehicles powered by SI engines. The differences between the values obtained with the acceleration value of $1.0 \mathrm{~m} / \mathrm{s}^{2}$ and the values with the real acceleration dynamics reach values of $5-10 \%$ in favor of the actual acceleration course. The same trends can be observed in the case of acceleration of cars with diesel engines, with the indication that the differences are slightly greater, and the minimum values were obtained during the most dynamic acceleration of the vehicle. Comparing the emission of $\mathrm{CO}_{2}$ according to the type of the used drive system, it can be stated that during the analyzed acceleration, cars powered by CI engines emit approx. 20-30\% less $\mathrm{CO}_{2}$ than cars powered by SI engines.

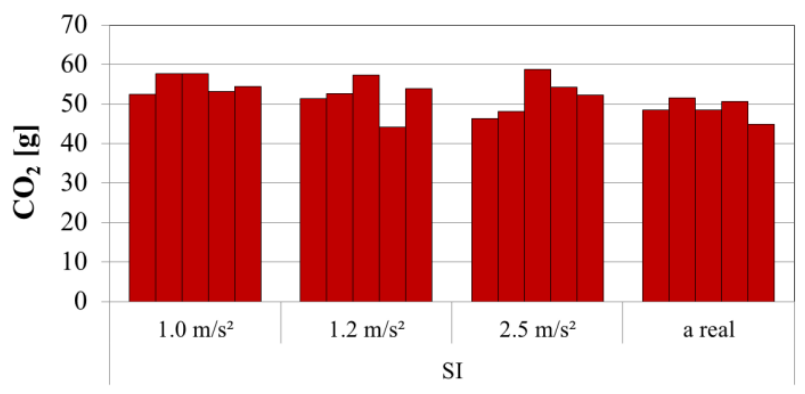

Fig. 19. $\mathrm{CO}_{2}$ emission for different acceleration characteristics of a vehicle propelled with SI Euro 3 engine obtained during simulation using PTV Vissim software

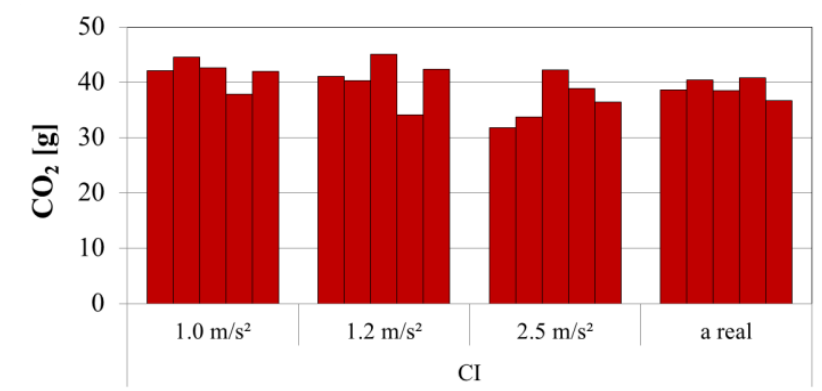

Fig. 20. $\mathrm{CO}_{2}$ emission for different acceleration characteristics of a vehicle propelled with CI Euro 3 engine obtained during simulation using PTV Vissim software 


\section{Conclusions}

Based on the simulation results, it can be concluded that the acceleration dynamics has a noticeable effect on the exhaust emissions from passenger cars during acceleration to $50 \mathrm{~km} / \mathrm{h}$. In the case of $\mathrm{CO}$, increasing the acceleration dynamics from 1.0 to $2.5 \mathrm{~m} / \mathrm{s}^{2}$ resulted in the reduction of the emission of this compound by even $20 \%$. The application of the acceleration dynamics based on real acceleration values, the results were ambiguous, because in the case of cars with SI engines, a reduction in $\mathrm{CO}$ emissions was recorded, reaching almost $30 \%$, while the use of a modified acceleration curve in cars with diesel engines resulted in an increase in $\mathrm{CO}$ emissions by approx. $20 \%$ compared to an acceleration of $1.0 \mathrm{~m} / \mathrm{s}^{2}$. Almost identical trends were observed during the analysis of the influence of the acceleration dynamics on $\mathrm{HC}$ emission. In the case of $\mathrm{NO}_{\mathrm{x}}$ emissions, increasing the acceleration dynamics also leads to inconclusive results, because for cars powered by SI engines there is even a $50 \%$ increase in the emission of this compound, while for cars with diesel engines, increasing the acceleration dynamics allows to reduce the emissions of this compound by even 15-20\%. The lowest emission val- ues were obtained for both types of drive systems for the actual acceleration process. The smallest differences in the vehicle acceleration dynamics function during the simulations were recorded for $\mathrm{CO}_{2}$ emissions (approx. 5-10\%).

The applied methodology is useful, for example, to assess the impact of vehicle acceleration dynamics or to compare the differences between different types of propulsion systems. Subsequent work should include the comparison of the vehicle acceleration emission values obtained during the simulation with the values obtained during the actual measurements. The measurements during road tests could give the possibility of verifying the concentrations of different exhaust compounds in exhaust gases.

\section{Acknowledgements}

The research was funded by European Union from European Regional Development Fund through the National Centre for Research and Development (Narodowe Centrum Badań i Rozwoju) - research project within the Smart Growth Programme (contract No. POIR.04.01.02-00-0002/18).

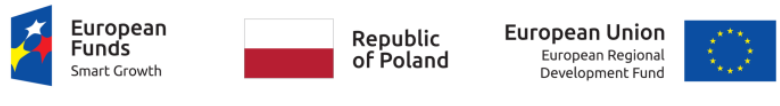

\section{Nomenclature}

$\begin{array}{llll}\mathrm{CI} & \text { compression ignition } & \mathrm{HC} & \text { hydrocarbons } \\ \mathrm{CO} & \text { carbon monoxide } & \mathrm{NO}_{x} & \text { nitrogen oxides }\left(\mathrm{NO}+\mathrm{NO}_{2}\right) \\ \mathrm{CO}_{2} & \text { carbon dioxide } & \mathrm{SI} & \text { spark ignition }\end{array}$

\section{Bibliography}

[1] ANDRZEJEWSKI, M. The influence of the driving style on the fuel consumption and exhaust emissions. Doctoral thesis. Poznan University of Technology. Poznan 2013.

[2] BULL, A. Traffic congestion: The problem and how to deal with it. United Nations, Economic Commission for Latin America and the Caribbean. Chile 2003.

[3] DONG, Y., XU, J., LIU, X. et al. Carbon emissions and expressway traffic flow patterns in China. Sustainability. 2019, 11, 2824. https://doi.org/10.3390/su11102824

[4] KURTYKA, K., PIELECHA, J. The evaluation of exhaust emission in RDE tests including dynamic driving conditions. Transportation Research Procedia. 2019, 40, 338-345. https://doi.org/10.1016/j.trpro.2019.07.050

[5] KREICBERGS, J., GAILIS, M., ZALCMANIS, G. et al. Traction energy and fuel consumption evaluation methodology in urban traffic. Proceedings of 23rd International Scientific Conference. Transport Means. 2019, Part I.

[6] Goolge Maps. maps.google.pl

[7] MERKISZ, J., ANDRZEJEWSKI, M., MERKISZ-GURANOWSKA, A. et al. The influence of the driving style on the $\mathrm{CO}_{2}$ emissions from a passenger car. Journal of KONES Powertrain and Transport. 2014, 21(3), 219-226. https://doi.org/10.5604/12314005.1133212

[8] MERKISZ, J., ANDRZEJEWSKI, M., PIELECHA, J. Comparison of carbon dioxide emissions in real traffic con- ditions of the vehicle with the values obtained in the certification test on the background of European standards. Combustion Engines. 2011, 3.

[9] NOWAK, M., ANDRZEJEWSKI, M., GALANT, M. et al. Simulation assessment of the selected combination of road and rail infrastructure in the aspect of choosing the route of road transport means. AIP Conference Proceedings Computational Technologies in Engineering (TKI'2018), 2019, 2078, 020055. https://doi.org/10.1063/1.5092058

[10] NOWAK, M., PIELECHA, J. Comparison of exhaust emission on the basis of real driving emissions measurements and simulations. MATEC Web of Conferences. 2017, 118, 00026. https://doi.org/10.1051/matecconf/201711800026

[11] Real world fuel economy measurements: technical insights from 400 tests of Peugeot, Citroen and DS cars. https://www.transportenvironment.org/

[12] SHRINDHAR BOKARE, P., KUMAR MAURYA, A. Study of effect of speed, acceleration and deceleration of small petrol car on its tail pipe emission. International Journal for Traffic and Transport Engineering. 2013, 3(4), 465478. https://doi.org/10.7708/ijtte.2013.3(4).09

[13] Traffic congestion: three big questions, three short answers. https://www.its.ucla.edu/for-the-press/traffic-congestion/

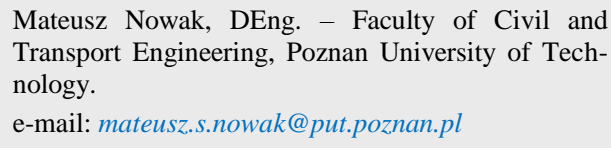

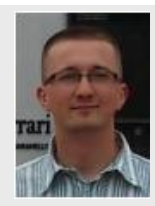

